\title{
"Experiência-narrativa" como sintagma de núcleo vazio: contribuiçóes para o debate metodológico na Saúde Coletiva
}

\section{| ${ }^{1}$ Ricardo Azevedo Pacheco, ${ }^{2}$ Rosana Onocko-Campos |}

Resumo: A produção e análise de narrativas é instrumental metodológico utilizado em estudos qualitativos em saúde coletiva. O presente artigo pretende situar alguns fundamentos para o emprego do conceito de experiência-narrativa como estratégia metodológicoconceitual para tal campo investigativo. A articulação paradoxal sempre presente entre os termos "experiência" e "narrativa" é investigada e situada teoricamente a partir do percurso do conceito em Walter Benjamin. Para esse autor, não há experiência exceto na linguagem. Esse é o ponto crucial a partir do qual experiência-narrativa é situada neste texto como sintagma de núcleo vazio, uma forma de cercar o incontornável paradoxo central da transmissão do espírito na linguagem. Isso permite qualificar as bases para o emprego do conceito como mediaçáo entre experiência e cultura e contribuir para o debate metodológico no campo da saúde coletiva.

> Palavras-chave: experiência; narrativa; metodologia; fundamentos; planejamento.

\author{
'Saúde Coletiva, Universidade \\ Estadual de Campinas. \\ Campinas-SP, Brasil \\ (ricardoazevedopacheco@yahoo. \\ com.br). \\ ORCID: 0000-0003-4015-9510 \\ 2 Saúde Coletiva, Universidade \\ Estadual de Campinas. Campinas- \\ SP, Brasil (rosanaoc@mpc.com.br). \\ ORCID: 000-0003-0469-5447
}

Recebido em: 11/05/2017

Aprovado em: 18/03/2018 Revisado em: 16/04/2018 


\section{Introdução}

A produção e a análise de narrativas vêm sendo utilizadas em estudos qualitativos em saúde coletiva como estratégia metodológico-conceitual para investigar e interpretar um campo vasto, mas que pode ser tomado como o campo - subjetivo por excelência - da mediação entre as experiências dos sujeitos e seus diferentes contextos, os discursos que produzem e que os produzem. Trata-se do:

[...] estudo de situaçôes nas quais interessem as mediaçôes entre experiência e linguagem, estrutura e eventos, sujeitos e coletivos, memória e ação política - questôes que tradicionalmente interessam à área de "Políticas, Planejamento e Gestão" da saúde coletiva brasileira (ONOCKO-CAMPOS; FURTADO, 2008, p. 1.090).

O uso de narrativas pode ser pensado para além de um instrumental metodológico. Trata-se de uma realização estética científica que redefine a relação entre pesquisadores e pesquisados (CASTELLANOS, 2014), na medida em que interessam os níveis interpretativos da leitura e das narrativas dos pesquisados e também do estilo e contexto narrativo dos pesquisadores. Tal perspectiva dialoga com a proposição da pesquisa narrativa como pesquisa-intervenção, o mesmo enquadre que pensa o campo da saúde coletiva atravessado pela presença da subjetividade, campo da clínica ampliada que "culmina com a idéia de autonomia" (PALOMBINI et al. 2013, p. 2.899). Isto, na prática, traduz-se pela ampliação da possibilidade de cogestáo dos pesquisados-narradores (usuários, formadores, formandos, trabalhadores ou gestores) em seus diferentes contextos.

Nesse sentido, o emprego de narrativas como estratégia metodológica tem valor também de tática política. Uma política-estética. Ao traduzir relações de poder (CHAGAS, 2014) entre os atores das práticas de saúde, as narrativas e narradores ganham a possibilidade de terem lugar nos centros de seus contextos de trabalho ou político-institucionais, podendo constituir uma forma de resistência a diferentes formas de "disciplinarização do corpo social" e de estratificação das práticas de cuidado (CASTELLANOS, 2014, p. 1.067), bem como produzir uma forma alternativa de construir o conhecimento ou avaliar serviços, dando voz àqueles que são objeto das intervençóes e que permanecem apagados dentro de uma perspectiva que do ponto de vista macro poderia ser chamada de médico-funcionalista.

Um exemplo claro disso pode ser a utilização da experiência-narrativa de usuários psicóticos de serviços substitutivos de saúde mental. Considerando a discrepância 
entre o discurso do psicótico e o discurso compartilhado (MIRANDA; ONOCKOCAMPOS, 2010), utilizar-se da narrativa desses usuários como pesquisa-intervenção pode incidir sobre a reformulação de projetos terapêuticos (PALOMBINI et al., 2013), sobre a ampliação da cogestão do usuário, sobre uso crítico do arsenal terapêutico medicamentoso (SERPA JR. et al., 2014), na avaliação de serviços etc. Tal impacto, em suas linhas gerais, está ligado à potência ético-política de "restituir aos sujeitos a autoria de discursos que os envolvem" (MIRANDA; ONOCKOCAMPOS, 2010, p. 441), o que também expressa a pretensão de que, ao se utilizar experiência-narrativa como método, alguma forma de subjetivação se produz do lado dos narradores.

O pesquisador também compartilha com aquele que se narra na experiência a posição de um interlocutor-narrador, como um "quem histórico" em seu testemunho sendo ambos, portanto, parte de uma "história efeitual", na acepção de Gadamer (apud ONOCKO-CAMPOS et al., 2013, p. 2.848), o que reforça a inserção desse tipo de metodologia como elemento-chave de epistemologias orientadas para ação social (CASTELLANOS, 2014, p. 1.070). Já no campo da formação clínica, sabe-se que a narratividade em jogo em apresentaçôes de caso, por exemplo, pode tornar-se um ideal formatado e fechado de texto a ser produzido e com valor de formação (CASTELLANOS, 2014. p. 1.071). No cenário da clínica e da formação clínica (raciocínio que pode ser estendido para a formação de equipes ou a formação de alunos nos contextos das redes de saúde, bem como para os processos de supervisão clínico-institucional), situar e interpretar os "textos e contextos produzidos pelos sujeitos nos encontros clínicos, e, deste modo, ampliar a dimensão dialógica e hermenêutica da prática clínica” (FAVORETO; CAMARGO, 2011, p.474) pode guardar a potência ético-política de questionar as balizas orientadoras das intervenções, problematizando o lugar conferido às situaçôes desviantes ou excessivas e seu enquadre sempre problemático no saber.

Se tais situações ou desvios não precisam ser apenas objeto de correção e têm uma narratividade própria, o que ensinam e em que ponto questionam o saber constituído ou as práticas estabelecidas? Essa pergunta, que traduz um pressuposto ético, permite vislumbrar a utilização da pesquisa-intervenção pelo levantamento e interpretação de experiências-narrativas no campo clínico, avaliativo, da supervisão clínica ou clínico-institucional ou da formação continuada, ou formação em serviço ou no uso do campo dos dispositivos públicos de cuidado como campo formador. 


\section{A questão conceitual}

Os termos "experiência" e "narrativa" são tomados geralmente como uma dupla que cumpre função de instrumental ou meio através do qual se acessam as experiências vividas dos sujeitos inseridos em uma coletividade linguística e os acontecimentos históricos de uma unidade temporal pela via de sua história relatada (SERPA JR. et al., 1999). Trata-se de uma divisão clássica, vida e narrativa, ou a narrativa como meio ou forma de acesso ao real. Conta-se a vida ou a experiência pela narrativa. As fontes de tal perspectiva são as das ciências sociais, que foram incorporadas heterogeneamente pelo campo das ciências em saúde.

De acordo com Castellanos (2014), as definiçôes do que vem a ser experiêncianarrativa variam com as perspectivas teóricas sobre o conceito, a pesquisa, objeto sob investigação, não existindo definições amplamente aceitas.

O formalismo russo, a perspectiva hermenêutica-fenomenológica de Ricoueur, a narratividade como ação social (Foucault, Bakhtin, Rorty) ou a historicidade de Benjamin são fundamentaçôes que não se superpõem. Os diferentes arranjos entre os polos "epistemológico, teórico, técnico e morfológico" (CASTELLANOS, 2014, p. 1.071) dirão qual o lugar e uso do conceito em questão na pesquisa qualitativa. Este cenário móvel permite perguntar qual a especificidade desse conceito.

Castellanos (2014) propóe genericamente que, do ponto de vista formal, narrativas se caracterizam pela ordenação sequencial de ações e eventos, e circunscrição de atores e cenários, colocando em relação contextos estruturantes e estruturados por elas, compondo unidades temporais que podem ser dispostas linearmente ou não. Destaca que a narrativa estabelece uma relação de sentido de "ser-no-mundo" (CASTELLANOS, 2014, p. 1.071), uma vez que estabelece, em diacronia, uma sequência mediada de unidades temporais do vivido.

O mesmo é destacado por Onocko-Campos ao dizer que narrativas são uma "forma de descrever experiências vividas" (ONOCKO-CAMPOS, et al., 2013, p. 2848) e que este caráter de "função mediadora" da narrativa é que interessa ao campo da Saúde Coletiva.

Dois artigos cuidadosos de revisão, de Hydén (1999) e Garro e Mattingly (1994), demonstram essa pluralidade na especificação do conceito, que pode ser dividida em dois grandes grupos: um valoriza os sistemas culturais de significação determinando 
a narratividade; o outro toma a experiência-narrativa como dimensão do vivido, e não apenas como abstração deste.

No segundo caso, o ponto filosófico e epistemológico a ser marcado e explorado neste artigo é o estatuto comum ou diferencial entre experiência e narrativa. Tratase de pensar a experiência pela narrativa ou da busca de uma redução e colocação de ambos os termos numa unidimensionalidade linguageira? Essa é a perspectiva que o rastreamento do conceito no percurso teórico do filósofo Walter Benjamin mostrará: não existe experiência, exceto na narrativa, ou seja, narrar é viver ou experimentar. Com isso, a potência da narrativa no aggiornamento de açôes sociais em seus contextos específicos fica sublinhada.

Afinal, por que o uso conjugado, mas pouco justificado, dos termos "experiência" e "narrativa"? São conceitos que se diferenciam, e nesse caso experiência e linguagem humana diferem em algum ponto. Há alguma razão para seu emprego como um sintagma linguístico único, ou haveria alguma outra via para situar tal relação? Tomese a questáo pelo ponto de vista gramatical. Experiência-narrativa é um sintagma. Sintagma é uma unidade sintática formada por elementos linguísticos contíguos em um enunciado. É composto de um ou mais vocábulos, que formam oraçôes ou uma unidade significativa. Podem ser verbais, nominais, adjetivais, adverbiais e preposicionais, de acordo com o núcleo do sintagma, elemento fundamental que ordena a unidade (CEGALLA, 1997). Experiência-narrativa é um sintagma que obedece a esse tipo de dependência e sequência? Trata-se, ao fundo, da questão mais ampla sobre o estatuto da linguagem como meio e é aí que a contribuição de Walter Benjamin mostra-se fecunda.

A ideia neste artigo é conceber esse sintagma chamando-o de sintagma de núcleo vazio, por assentar-se no paradoxo intrínseco ao fenômeno da linguagem. A trilha da articulação experiência-narrativa (erfahrung, erlebnis) em Walter Benjamin, filósofo e crítico literário alemão que produziu, ao longo de sua obra, particularmente nas primeiras três décadas do século $\mathrm{XX}$, um percurso do qual se pode recolher a fundamentação, permite especificar assim o sintagma em questão.

Em Benjamin (GURGEL, 2014), a linguagem não pode ser considerada nem instrumento de elaboração dos dados da realidade (meio de acesso), tampouco simples abstração. Ela é o único campo possível para a emergência de relaçôes entre narrativa e experiência. No texto princeps de 1916, "Sobre a linguagem em geral e 
sobre a linguagem do homem” (BENJAMIN, 2013a), o filósofo expõe sua concepção de linguagem a partir de um núcleo paradoxal: não existe experiência espiritual fora da linguagem, mas esta não se superpóe por completo ao espírito. Um paradoxo.

O conceito de Erfahrung (experiência) atravessa a obra de Benjamin, desde um texto de juventude, de 1913 (BENJAMIN, 2014), às teses de seu texto último acerca do tema, em 1940 (BENJAMIN, 1989), quando discorre sobre o escritor Charles Baudelaire. No intervalo, na década de 1930 (BENJAMIN, 2012a; BENJAMIN, 2012b), a conceitualização de experiência-narrativa se constrói a partir do sinal da época desse período entre-guerras: a perda da narratividade tradicional correspondente à reformulação da experiência estético-literária, que fundou a literatura moderna.

A questão do paradigma estético é fundamental nos termos benjaminianos (GURGEL, 2014).Algunsveem em Benja min a morte do narrador(CASTELLANOS, 2014). Não se trata disso. O filósofo coloca para a contemporaneidade a necessidade de forjar novas formas de narrar com o que dispomos. As obras de escritores como Kafka e Baudelaire são paradigmas para Benjamin de estilos em que narrar sob a égide da experiência contemporânea, em vez da narratividade tradicional, foram bem-sucedidos.

A primeira vez que Walter Benjamin (2014) fala de experiência é no artigo de 1913, "Erfahrung", aos 21 anos. Naquela época, Benjamin e parte da juventude berlinense acreditavam na necessidade de uma reforma pedagógica ampla na cultura alemã e que a reformulação na mentalidade dos jovens seria essencial para isso (LIMA; BAPTISTA, 2013). Nesse texto, o jovem filósofo dialoga com a máscara do adulto que já experimentou de tudo. Experiência, ou erfahrung, surge na concepção do filósofo ligada a essa voz do adulto usada de forma a anular as chances do novo. Ao tomar partido da desilusão com tudo o que viveu, o adulto atribui a si a prerrogativa de dizer que, por mais que um jovem tente, haverá apenas um sentido unívoco e universal a ser conferido à vida. Essa voz diz que a vida é vulgar e sem sentido. Resposta brutal, coerente com o clima das vésperas da Guerra. O embate do jovem Benjamin no início do século XX é: "Travamos nossa luta por responsabilidade contra um ser mascarado. A máscara do adulto chama-se 'experiência'. Ela é inexpressiva, impenetrável, sempre a mesma” (BENJAMIN, 2014, p. 21).”

O fato de Benjamin inaugurar a noção de experiência com esse diálogo situa um aspecto do conceito, que se manterá na obra e que corrobora a perspectiva da incidência das experiências narrativas como ação de resistência. Questionando a 
voz do adulto (símbolo de qualquer discurso hegemônico) a Erfahrung inaugura-se como uma atitude de resistência que o autor sustentará até o final. Essa resistência, porém, não pressupóe o ultrapassamento desse diálogo com a voz do adulto como uma ruptura ou um ideal revolucionário. Trata-se de resistir dentro do campo desse diálogo, ou seja, instituir uma narrativa "menor", contrapondo-se a qualquer contexto de silenciamento. Por qual via se poderia resistir no diálogo?

Se não existe outra possibilidade além do campo de diálogo com a máscara da experiência, não se pode comprar o peixe pelo preço - sem esperança - que o adulto vende. Há que se colocar em questáo, sem ideais revolucionários, o estilo de linguagem da resposta do adulto. Esse estilo é o da ausência de espírito. É ela que dá à voz do adulto seu caráter desesperador. A saída para Benjamin está na linguagem: uma coisa é a versão da experiência do adulto, outra é a experiência no espírito.

Mas por que entáo a vida é absurda e desconsolada para o filisteu? Porque ele só conhece a experiência, nada além dela; porque ele próprio se encontra privado de consolo e de espírito (BENJAMIN, 2014 p. 22).

A experiência engendrada no espírito é vivificadora, não transcendente e inerente à própria dimensão da experiência como linguagem. O texto de 1916, "Sobre a linguagem em geral e sobre a linguagem do homem", dá o passo seguinte na formalização disso. Ele sustenta, ao pensar as bases da linguagem humana, a indissociabilidade (algo unidimensional, portanto) paradoxal entre "experiência" e "narrativa". Benjamin (2013a, p. 49) diz "toda vida espiritual humana pode ser concebida como uma espécie de linguagem" e articula esta afirmação com outra, contraditória: “a "essência espiritual que se comunica na língua não é a própria língua” (BENJAMIN, 2013a, p. 51). Um descentramento na linguagem, que, porém, não permite inferir que a essência espiritual seja inefável.

Esse paradoxo insolúvel da articulaçáo entre os termos do sintagma experiêncianarrativa é o vazio central pelo qual se enodam essas duas dimensóes, de forma que só se pode dizer de experiência na narrativa. Então, o núcleo desse sintagma não reside num ou noutro termo, mas no paradoxo que permite qualificá-lo, fora da convenção gramatical, como sintagma de núcleo vazio. Cada termo bordeia seu vazio central. Tal é o eixo do texto de 1916: não há experiência fora da linguagem, a essência espiritual não é a própria língua mas só é capturável e transmissível nela, na língua. 
Seguindo passo a passo a lógica da argumentação de Benjamin e recortando a sequência do que é elaborado ali:

Passo um: a abrangência da linguagem humana e a delimitação da linguagem em sua particularidade de palavra.

Resumindo: toda comunicação de conteúdos espirituais é língua, linguagem, sendo a comunicação pela palavra apenas um caso particular: o da comunicação humana e do que a fundamenta ou do que se funda sobre ela (a jurisprudência, a poesia). Mas a existência da linguagem estende-se não apenas a todos os domínios de manifestação do espírito humano, ao qual, num sentido ou outro, a língua sempre pertence, mas a absolutamente tudo (BENJAMIN, 2013a, p. 50-51).

Passo dois: delimitando o paradoxo. Conteúdos espirituais só se comunicam na linguagem, mas a essência espiritual não se superpõe à essência linguística. Um não existe sem e não coincide com o outro. Para o autor, supor essa coincidência (a linguagem dizendo a essência espiritual de uma coisa) é como um abismo que ameaça engolir a teoria da linguagem. Benjamin faz uma recomendação de método: manter-se em suspenso sobre esse abismo, sustentando que esse descentramento é uma questão de princípio que deve ser mantida como fundamento para quaisquer investigaçóes no campo da teoria da linguagem. Ao propor que a comunicabilidade do espírito ocorre na língua, e não por meio da língua, Benjamin especifica o que poderá se desdobrar do uso investigativo da narratividade como meio: sustentar metodologicamente o paradoxo da língua é impasse, mas também solução.

A diferenciação entre a essência espiritual e a essência linguística na qual aquela se
comunica é a distinção primordial em uma investigação de caráter teórico sobre a lin-
guagem; e essa diferença parece ser tão indubitável, que, ao contrário, a identidade
entre a essência espiritual e a linguística, tantas vezes afirmada, constitui um profundo
e incompreensível paradoxo para o qual se encontrou expressão no duplo sentido da
palavra logos. E no entanto, esse paradoxo, enquanto solução, ocupa um lugar central
na teoria da linguagem, permanecendo paradoxo e insolúvel quando colocado no início
(BENJAMIN, 2013a, p. 52).

O que comunica a língua?, pergunta Benjamin. "Ela comunica a essência espiritual que lhe corresponde" (BENJAMIN, 2013a, p. 52). Embora a resposta pareça objetiva, é decisivo saber que essa essência comunica-se na língua, e nunca pela língua. Benjamin insiste no uso da preposição "em" ou "na" para dizer do engendramento da experiência na narrativa. "A essência espiritual só é idêntica à essência linguística na medida em que é comunicável” (BENJAMIN, 2013a, p. 52). 
Passo três: a especificidade da linguagem. Se o espírito das coisas e linguagem articula-se pela via do paradoxo, é necessário recolocar a questáo da linguagem como meio. Benjamin rejeita o repatriamento do fenômeno linguístico entre emissor, destinatário e objeto, balizas que orientam a perspectiva do acesso à experiência pela narrativa. Dirá que esse repatriamento corresponde a uma falsa concepção da linguagem A linguagem é meio na medida da imediaticidade de sua comunicação e de sua relação direta com Deus. Não é modo de comunicação entre um emissor e um destinatário. Nesse sentido, a comunicabilidade da linguagem não é referida ao seu conteúdo. O comunicável não é o compreensível, e o compreensível não é o transmissível em Benjamin.

A essência da linguagem humana que a distingue é seu caráter nomeante. Essa função em exercício comunica com Deus, instância criadora do nome enquanto tal. A comunicabilidade em jogo então não gira em torno da correspondência nome-objeto, mas da articulação nome-função nomeante, delimitável no campo linguístico. A questão da comunicabilidade gira em torno daquilo que se obtém como efeito do exercício nessa função nomeante.

Aquilo que é comunicável em uma essência espiritual é imediatamente aquilo que nela é comunicável. Aquilo que é comunicável em uma essência espiritual é aquilo no que ela se comunica; o que quer dizer que toda língua comunica a si mesma. Ou melhor: toda língua se comunica em si mesma. Ela é no sentido mais puro o meio [Médium] da comunicação (BENJAMIN, 2013a, p. 53).

Passo quatro: a questão da natureza dessa comunicação espiritual com Deus. O problema originário da linguagem é sua magia. Benjamin navega na fronteira entre teoria da linguagem e filosofia da religião. Se o espírito comunica-se na língua, a língua não pode ser medida nem limitada. A quem se comunicam a lâmpada ou a raposa? Ao homem. E a quem o homem se comunica? A outro homem. Esse seria o caminho para a concepção falsa de linguagem: o homem comunica-se pelo nome que dá às coisas. O que Benjamin propóe é diferente: no nome, a essência espiritual comunica-se a Deus. A essência linguística é essa comunicabilidade.

Em Deus, o nome cria. A palavra divina nomeia e cria ao nomear. É essa conexão criativa com a nomeação que articula experiência-narrativa unidimensionalmente. Narrar é criar. Porém, só Nele (Deus, nome) há relação absoluta entre nome e conhecimento. Ao criar com o nome, Deus soube que aquilo era bom. Deus é o nome dessa operação suposta em que o nome criador é conhecimento. O homem, 
porém, padece de uma precariedade em sua relação à linguagem. Deus depositou nele sua capacidade criadora. Mas ele não poderá manter com a linguagem a mesma relação absoluta em termos do saber. A essência espiritual do homem é a linguagem, onde ocorreu a criação, mas é criação em potência. Haverá sempre um inexprimível experimentado pelo homem, como uma suposta "última essência espiritual" (BENJAMIN, 2013a, p. 59).

Benjamin chamará essa mágica paradoxal da comunicação com o inexprimível de "revelação". O inexprimível se diz como revelação. Ou, em outros termos, a "última essência espiritual" é nome, mas, ao mesmo tempo, espírito. Com a noção de "revelação", Benjamin cerca um paradoxo ou um impossível lógico que é transmissível na medida em que não compreensível, mas revelado.

No interior de toda configuração linguística reina o conflito do expresso e do exprimível com o inexprimível e o inexpresso. Ao vislumbrar esse conflito vislumbra-se na perspectiva do inexprimível, simultaneamente, a última essência espiritual. [...] É exatamente isso que significa o conceito de revelação quando toma a intangibilidade da palavra como condiçáo única e suficiente - e a característica do caráter divino da essência espiritual que nela se exprime (BENJAMIN, 2013a, p. 59).

\section{Benjamin, anos 1930}

Os principais textos de Benjamin sobre o sintagma de núcleo vazio nos anos 1930 (FELMAN, 2014; GAGNEBIN, 2012, 2013) são "Experiência e pobreza”, de 1933 (BENJAMIN, 2012a), e "O narrador: consideraçôes sobre a obra de Nikolai Leskov", de 1936 (BENJAMIN, 2012b). Esse percurso termina com "Sobre alguns temas em Baudelaire”, de 1940 (BENJAMIN, 1989). Nos dois primeiros, o sintagma apresenta a faceta de outro paradoxo que repete seu paradoxo de fundamento. Benjamin vai costurar experiência-narrativa a partir da perda da narrativa tradicional vivida no silenciamento decorrente da experiência traumática da Primeira Guerra. Qual a significação desse fenômeno em termos da reconfiguração do estilo da experiêncianarrativa moderna e contemporânea? É a sua pergunta.

Não, está claro que as ações da experiência estão em baixa, e isso numa geração que entre 1914 e 1918 viveu uma das mais terríveis experiências da história universal. [...]. Na época, já se podia notar que os combatentes voltavam silenciosos do campo de batalha. Mais pobres em experiências comunicáveis, e não mais ricos. Os livros de guerra que inundaram o mercado literário dez anos depois continham tudo menos experiências transmissíveis de boca em boca. Não, o fenômeno não é estranho. [...] Uma geração que ainda fora à escola num bonde puxado por cavalos viu-se sem teto, numa paisagem diferente em tudo, exceto 
nas nuvens, e em cujo centro, num campo de forças de correntes e explosóes destruidoras, estava o frágil e minúsculo corpo humano (BENJAMIN, 2012a, p. 123-124).

Benjamin constrói uma ligação entre o silenciamento imposto à experiêncianarrativa com a Primeira Guerra e a morte da tradição narrativa na sociedade capitalista moderna. Em "Para uma crítica da violência", Benjamin (BENJAMIN, 2013b, p. 121-156) nos ensina que, independente do modo como atua uma causa, "ela só se transforma em violência, no sentido pregnante da palavra, quando interfere em relaçóes éticas” (BENJAMIN, 2013b p. 121). O que está em questão é a perda de algo da ordem da humanidade, que diz respeito à condição humana na linguagem. $\mathrm{O}$ antiético em questão na Guerra é a imposição criminosa de uma experiência inenarrável.

Segundo Felman (2014), trata-se, para Benjamin, de um convite no sentido inverso: como cercar, com uma nova narratividade, a impossibilidade em jogo na escrita da catástrofe, ou como traduzir o intraduzível da guerra. O filósofo toma a impossibilidade de narrar como ponto de partida para pensar a mutaçáo da experiência-narrativa nas sociedades modernas capitalistas e, por decorrência, na contemporaneidade, insistindo na vertente de uma simbolização, mas em outro estilo.

Em "Experiência e pobreza", Benjamin (2012a) diz que o "desmentido" da experiência das guerras se estendeu à coletividade dos homens e engendrou uma nova forma de narrar. Trata-se da "nova forma de miséria", da "queda das ações da experiência” (BENJAMIN, 2012a, p. 124) da sociedade moderna nascente. A cultura que produziu a tecnologia e o silencio da guerra, transformou-se em uma cultura coletiva de vidro e aço que são, para Benjamin, materiais avessos ao traço e ao rastro, tornando-se avessa à narrativa tradicional e propícia ao esquecimento sistemático e em larga escala. Essa mesma época, porém, forneceu aos novos narradores essa "moeda miúda do atual", para que "no meio tempo, possa o indivíduo dar um pouco de humanidade àquela massa, que, um dia, talvez retribua com juros e com os juros dos juros" (BENJAMIN, 2012a, p. 128). Se Benjamin insiste na retomada da narrativa em nova moeda, isso se deve à insistência, em sua obra, de um princípio básico: insistir na experiência-narrativa é insistir na vida, uma vez que narrar é experimentar.

Essa moeda miúda, unidade comunicativa contemporânea, Benjamin chama de erlebnis. Se, por um lado, ela é avessa à narratividade da tradição, o novo contexto exige reinvenção e pede as contas para essa nova forma de narratividade. Tal como 
em 1913 era incontornável o diálogo com o adulto, nesse momento a pergunta é: como produzir narrativa na momentânea, fugaz e instantânea erlebnis (vivência) própria à solidão pulverizada, privatizante e individual das massas? Cumpre dizer aqui que não é outra a moeda em uso e com a qual a pesquisa narrativa com usuários ou profissionais do campo da saúde coletiva se encontra.

Para Benjamin, a autoridade do narrador e a eficácia da narratividade tradicional sempre estiveram ligadas à proximidade com a morte, o moribundo é o exemplo maior desse narrador. A narração tradicional tem sua figura autoridade derivada dessa zona indistinta de fronteira entre vida e morte. É o pathos da "permuta última" (FELMAN, 2014, p. 56) entre moribundo e vivo. Daí advém o valor do conselho e da vontade anunciada daquele que está prestes a morrer. O moribundo encarna o inominável da fronteira vida-morte e esse desejo de continuidade que deriva da própria perda.

A forma atual de narrativa, cujo protótipo é a informação jornalística, tem como cenário um contexto social que expulsou a morte do espaço público. A morte no front era anônima, destituída de um lugar ritual estabelecido no corpo social. Tal como a morte isolada nos hospitais, a morte passou a ser asséptica, breve, fugaz. Expulsa, ela volta de outro jeito. É o desvanecimento da informação na produção incessante, no consumo e descarte da notícia, seu esquecimento e desfalecimento intrínsecos, a via pela qual a morte se renova sem parar na descartabilidade das coisas. Eis o que caracteriza a erlebnis das sociedades modernas.

Jean Marie Gagnebin (2013) situa sucintamente essa passagem da erfahrung à erlebnis, dando ênfase à insistência do autor na reconstrução da narratividade como forma de estabelecer algum laço possível no contexto da solidão massificada. Nesse sentido, pensando no campo da saúde coletiva e do trabalho em equipe, a narrativa pode constituir uma equipe onde às vezes se encontra um grupo fragmentário:

Nos textos fundamentais dos anos de 1930 [...] Benjamin retoma a questão da "Experiência”, agora dentro de uma nova problemática: de um lado demonstra o enfraquecimento da Erfahrung no mundo capitalista moderno em detrimento de um outro conceito, a Erlebnis, experiência vivida, característica do indivíduo solitário; esboça, ao mesmo tempo uma reflexão sobre a necessidade de sua reconstrução para garantir uma memória e uma palavra comuns, malgrado a desagregação e o esfacelamento do social. O que nos interessa aqui, em primeiro lugar, é o laço que Benjamin estabelece entre o fracasso da Erfahrung e o fim da arte de contar, ou dito de maneira inversa (mas náo explicitada em Benjamin), a ideia de que uma reconstrução da Erfahrung deveria ser acompanhada de uma nova forma de narratividade (GAGNEBIN, 2013, p. 56). 
No cenário do pós-guerra, as condiçôes da erfahrung não se sustentam mais nas figuras de seus representantes ancestrais, simplesmente porque elas foram expulsas ou não têm mais legitimidade no corpo social. As figuras do narrador tradicional e o lugar social da morte mudaram de estatuto. A bola da vez está com o cidadão comum, dos grandes centros urbanos, personagens de Baudelaire, ou nos burocratas e alvos dos movimentos incompreensíveis do poder, desiludidos da autoridade de Kafka. Sob essa perspectiva, quem sustentará na asséptica, imediata e fragmentária sociedade capitalista uma narração somos nós. O sintagma de núcleo vazio mantém sua potência criativa e nomeante, Benjamin mantém sua direção metodológica de forma que não é apenas nostálgica (GAGNEBIN, 2013), indicando seu deslocamento para o cenário do comum e do cotidiano a trabalho da resistência. O cenário dos dispositivos de cuidado em saúde é visível aqui.

Em 1933 e 1936, Benjamin lança a questão: de que ordem é a reestruturação da experiência através de sua abordagem de novas formas de narratividade possíveis em nosso tempo, aquelas que forjaram a literatura moderna. Baudelaire, um lírico no auge do capitalismo, um autor que conseguiu uma fórmula literária capaz de fazer narrativa com os cacos da narratividade tradicional dentro da aglomeração de indivíduos solitários, no contexto da sociedade de massas urbanizada, é seu paradigma do novo narrador. Esse escritor (BENJAMIN, 1989, p. 103) é um autor que não rejeita a "determinação histórica da experiência" ou "a experiência inóspita e ofuscante da época da industrialização em larga escala”. Exatamente nesse contexto e com ele, Baudelaire "pretendia ser compreendido" (BENJAMIN,1989, p. 104), e conseguiu lirismo, ou seja, experiência-narrativa, no capitalismo.

O luto da experiência narrada nos contornos das sociedades pré-capitalistas, a "arte perdida" (FELMAN, 2014, p. 54) da transmissão do moribundo para seus herdeiros, do viajante para a comunidade, a do camponês para seus pares, serve ao filósofo para diagnosticar a pobreza da experiência e a experiência da pobreza de nosso tempo. A pobreza da experiência diz respeito ao deslocamento literário entre a narrativa enquanto busca de transmissáo transgeracional e comunitária de um valor útil ou práxico (erfahrung) (GAGNEBIN, 2012) para a solitária, desmemoriada e não comunicativa erlebnis moderna.

A solução encontrada por Charles Baudelaire é paradigmática, pois esse autor foi um traumatófilo (BENJAMIN, 1989), ou seja, produziu um estilo que conseguiu incluir na experiência-narrativa de sua época o inenarrável, produzindo 
uma ação social que se traduziu na comunicabilidade com seu público. Em certo sentido, para Benjamin, Baudelaire levou ao extremo a experiência da pobreza. Baudelaire (2012) foi um autor que conseguiu produzir metáfora utilizando-se dos elementos fragmentários e desagregados, incluindo-se, e com isso safando-se, na erlebnis. No primeiro verso de suas Flores do Mal, o escritor chama seu leitor de irmão, demonstrando uma vetorização mais horizontal na comunicabilidade com ele. Aplica-se a esse autor o que Gagnebin diz que outro escritor, Franz Kafka, representa também para Benjamin: "a mais perfeita narração contemporânea da impossibilidade de narrar” (GAGNEBIN, 2013. p. 66).

Este artigo não entrará nos meandros complexos do texto de Benjamin sobre a erlebnis e Baudelaire. Basta situar que o filósofo faz uma investigação detalhada sobre a memória, que começa em Bergson, passa por Proust (memória involuntária), para buscar sua fundamentação em Freud de 1920, no "Mais além do princípio do prazer" (FREUD, 1969).

Dançando com Freud, Walter Benjamin afirma a não reciprocidade e o antagonismo entre consciência e memória para situar a memória da experiêncianarrativa em outras bases que não as da voluntariedade ou da atenção. A consciência faz barreira à memória involuntária, e esta é desencadeada pelos choques acidentais com os objetos, tal como Proust desencadeia o influxo descritivo de Em busca do tempo perdido com o choque do cheiro da Madeleine. Baudelaire seria um traumatófilo na medida em que manteria essa disposição e essa abertura ao choque com o objeto, decaído, porém de uma posição de autoridade ou ideal, que corresponderia à aura do narrador ou da obra de arte. Um narrador que consentiria, como o filósofo postula, em sua própria perda:

A narrativa [...] é ela própria, num certo sentido, uma forma artesanal de comunicação. Ela não está interessada em transmitir o "puro em si" da coisa narrada, como uma informação ou um relatório. Ela mergulha a coisa na vida do narrador para em seguida retirá-la dele. Assim, imprime-se na narrativa a marca do narrador, como a máo do oleiro na argila do vaso (BENJAMIN, 2012b, p. 221).

A narrativa engendra a experiência somente a partir de um "dar de si”, permitindo sua transmissibilidade e indicando alguma perda, que incide também do lado de quem narra, o que é conflituoso. Trata-se, portanto, de construir, em perda, sob a égide da resistência, o estilo de um autor-narrador singular em comunidade com seu tempo e seus irmáos (BENJAMIN, 1989) e, com isso, de seguir o conselho, tão caro 
a Benjamin, de sustentar a potência da experiência-narrativa como transformadora (GAGNEBIN, 2012, p. 63). Baudelaire é um autor que assumiu e pagou seu preço para cercar, domesticar o impossível que ronda a impossibilidade narrativa no nosso tempo: incluiu-se na erlebnis, de forma horizontal aos seus pares, para subtrair-se.

\section{Considerações finais}

A pesquisa qualitativa é útil quando se pergunta sobre o "como" e o "por que" dos objetos históricos sobre os quais se quer interrogar. Tais objetos estão sempre inseridos num contexto histórico específico, são particulares e pouco ou nada reprodutíveis. Dentro dessa perspectiva, o desenvolvimento deste tipo de pesquisa implica, a partir da relação pesquisador-pesquisado, o levantamento ou o recorte e interpretação dos seus objetos, ao contrário de uma perspectiva que colocaria uma fronteira epistemológica clara entre o conhecimento e a realidade em si (ONOCKOCAMPOS, 2011).

Este é o enquadre maior dentro do qual se insere a contribuição deste artigo: o sintagma de núcleo vazio experiência-narrativa. Se o objeto de interrogação da pesquisa qualitativa não está dado, mas se produz, interessa circunscrever as condiçôes e balizas teóricas dentro das quais essa, e não outra produção, se realiza. No caso, interessa ter clareza sobre a fundamentação filosófica, ética e epistemológica que permite a concepção de um tipo de produção, construção, pesquisa e interpretação de narrativas, bem como delinear as consequências desta escolha metodológica.

Num outro artigo, as contribuiçôes das perspectivas de Paul Ricoeur, Walter Benjamin e da antropologia médica foram traçadas (ONOCKO-CAMPOS et al., 2013). Dele, dois aspectos de largo escopo da contribuição da perspectiva benjaminiana para essa discussão de método para o campo da investigação em saúde coletiva podem ser recortados. O primeiro é da ordem de um argumento filosófico-epistemológico, mas que tem consequências em termos do postulado deste tipo de pesquisa com narrativas como pesquisa-intervenção (PALOMBINI et al., 2013) ou a elaboraçáo sobre a performatividade da produção narrativa, suas chances de incidência no agir (CASTELLANOS, 2014). Se com Hannah Arendt é possível dizer que viver é narrar (KRISTEVA, J., 2002) defende-se aqui que com Benjamin é possível pensar que narrar é viver, uma vez que a experiência do homem transmite-se unicamente na linguagem ou no campo da linguagem sem, porém, coincidir com este, ou seja, trata- 
se de uma aposta na condição criativa e na pesquisa-intervenção com narrativas como “estratégia participativa” (ONOCKO-CAMPOS, 2011, p. 1.272).

$\mathrm{O}$ segundo diz respeito a um esclarecimento que o percurso benjaminiano oferece quanto ao "como" pode-se pensar esse potencial de resistência, ação ou estranhamento (ONOCKO-CAMPOS, 2011, p. 1.271). Tomar experiêncianarrativa como sintagma de núcleo vazio significa tomar partido do que está em seu núcleo: o paradoxo da nomeação. Tomado assim, o conceito de narrativa gira em torno de algo que, embora seja tangenciável, não pode ser objeto de uma denominação, classificação ou explicação exaustivas, o que está ligado tanto ao aspecto da construção quanto da interpretação das narrativas.

Quanto à construção das narrativas, ler Benjamin permite outra recomendação de método: ater-se à literalidade, ao manifesto, mas não no sentido meramente transcritivo, mas do que se desenha como impossibilidade ou contradição lógicodiscursiva no processo de construção das narrativas. O fracasso clínico ou terapêutico, o conflito institucional, os paradoxos da política, as tensôes intra ou inter-equipes, os pontos cegos dos discursos ou dos ideais fundantes das instituiçôes ou orientadores das práxis são nomes possíveis que bordejam este impasse central. Vale lembrar que, para o filósofo, o paradoxo da língua é impasse, mas também solução: não descartá-lo, fazer com ele. Isso implica uma atitude ética em relação aos narradores (pesquisadores e pesquisados): rejeitar a violência ou a autoridade interpretativa (ONOCKOCAMPOS, 2011, p. 1.283) e propor uma ordenação lógica e não apenas cronológica na construção do narrado. Uma lógica que não se furte aos seus próprios impasses nem aos dos pesquisados, dos pesquisador e ou de suas referências teórico-práticas.

Quanto à interpretação. Se, de acordo com a leitura proposta aqui, náo existe experiência fora da narrativa e a narrativa já é, em si, o produzir de uma experiência, não se trata de separar experiência, ou vivido de cultura ou narrado, mas de deslocar o foco da investigação para o que é dito e como é dito, seja pelo pesquisador narrador ou sobre o pesquisado (usuário, membro de equipe, aluno, formador, supervisor), entendendo que este dizer já é a experiência e nossas possíveis interpretaçôes, um desdobramento disso, ou seja, este ou aquele campo de saber atravessado e interrogado por esse dizer, o que inverte o polo ético habitual das investigaçôes.

Pesquisa-se e interpreta-se com o narrador e com o narrado e a interpretação deixa de ser explicação, passando a ser colocada, em sua relaçáo com o saber ao qual se refere, sob questão. Nesse sentido, Interpretar com o outro e não sobre ele, implica 
colocar também o pesquisador e seu instrumental sob o foco de interrogaçôes a serem formuladas e o trabalho de respondê-las. O impasse e a contradição ou a exploração das diferentes versóes narrativas dos impasses podem levar a um tipo de mudança pactuada, cogerida, e na acepção deste artigo, legítima de um ponto de vista po-ético. ${ }^{1}$

\section{Referências}

BAUDELAIRE, C. As flores do mal. Trad. Ivan Junqueira. Rio de Janeiro: Nova Fronteira, 2012. BENJAMIN, W. Sobre alguns temas em Baudelaire (1940). In: Obras escolhidas III. Charles Baudelaire, um lírico no auge do capitalismo. Trad. José Carlos Martins Barbosa e Hemerson Alves Baptista. São Paulo: Editora Brasiliense, 1989, p. 103-151.

. Experiência e pobreza (1933). In: Obras escolhidas, ensaios sobre literatura e história da cultura. V. 1. Trad. Sérgio Paulo Rouanet. São Paulo: Editora Brasiliense, 2012a, p. 123-129.

. O narrador: consideraçóes sobre a obra de Nikolai Leskov (1936). In: Obras escolhidas, ensaios sobre literatura e história da cultura. V. 1. Trad. Sérgio Paulo Rouanet. São Paulo: Editora Brasiliense, 2012b, p. 213-241.

. Sobre a linguagem em geral e sobre a linguagem do homem. In: Escritos sobre mito e linguagem (1915-1921). Trad. Susana Kampf Lages e Jeanne Marie Gagnebin. São Paulo: Editora 34, 2013a, p. 49-73.

. Experiência. In: Reflexôes sobre a criança, o brinquedo e a educação. São Paulo: Editora 34, 2014, p. 21-27.

. Para uma crítica da violência. In: Escritos sobre mito e linguagem (1915-1921). Trad. Susana Kampf Lages e Jeanne Marie Gagnebin. São Paulo: Editora 34, 2013b.

CASTELlANOS, M. E. P. A narrativa nas pesquisas qualitativas de saúde. Ciência e Saúde Coletiva. Rio de Janeiro, v. 19, n. 4, abr. 2014.

CHAGAS, R. As narrativas de vida como ferramenta para a formação e a pesquisa em educação e saúde. Divesitates International Journal. Revista de saúde coletiva e bioética da Universidade Federal Fluminense, v. 6, n. 2, dez. 2014.

CEGALLA, D. P. Novíssima Gramática da Lingua Portuguesa. São Paulo: Editora Nacional, 1997. FAVORETO, C. A. O.; CAMARGO, K. R. J. A narrativa como ferramenta para o desenvolvimento da prática clínica. Interface, comunicação, saúde, educação, v. 15, n. 37, p. 473-483, 2011.

FELMAN, S. O inconsciente jurídico. Julgamentos e traumas no século XX. Trad. Ariani Bueno Sudatti. São Paulo: Edipro, 2014.

FREUD, S. Mais além do princípio do prazer. In: Edição standard brasileira das obras psicológicas completas de Sigmund Freud. Vol. XVIII. Rio de Janeiro: Imago, 1969[1920]. 
GAGNEBIN, J. M. Walter Benjamin ou a história aberta. In: BENJAMIN, W. Magia e técnica, arte e política. Trad. Sergio Paulo Rouanet. São Paulo: Brasiliense, 2012. (Obras Escolhidas, 1). . História e narração em Walter Benjamin. São Paulo: Perspectiva, 2013.

GARRO, L. C.; MATTINGLY, C. Narrative Representations of Illness and Healing. Social Science Medicine. [s. 1.], v. 6, n. 38, p. 771-774, 1994.

GURGEL, E. P. Experiência e linguagem em Walter Benjamin. Educ. Pesquisa. São Paulo, v. 40, p. 3, 2014.

HYDEN, L. C. Illness and narrative. Sociology of Health \& Illness. [s. 1.], v. 1, p. 19, p. 48-69, 1999.

KRISTEVA, J. O gênio feminine: a vida, a loucura, as palavras. Tomo I: Hannah Arendt. Rio de Janeiro: Rocco, 2002.

LIMA, J. G.; BAPTISTA, L. A. Itinerário do conceito de experiência na obra de Walter Benjamin. Princípios - Revista de Psicologia. Natal, v. 20, n. 33, p. 449-484, jan./jun. 2013.

MIRANDA, L.; ONOCKO-CAMPOS, R. Narrativas de pacientes psicóticos, notas para um suporte metodológico de pesquisa. Rev. Latinoam. Psicopat. Fundamental, v. 3, n. 13, p. 441456, 2010.

ONOCKO-CAMPOS, R. Fale com eles! O trabalho interpretativo e a produção de consenso na pesquisa qualitativa em saúde: inovaçóes a partir de desenhos participativos. Physis, Revista de Saúde Coletiva. Rio de Janeiro, v. 21, n. 4, p. 1.269-1.286, 2011.

ONOCKO-CAMPOS, R.; FURTADO, J. Narrativas: utilização na pesquisa qualitativa em saúde. Revista de Saúde Pública. São Paulo, v. 42,n. 6, p. 1.090-1.096, 2008.

ONOCKO-CAMPOS et al. Narrativas no estudo das práticas em saúde mental: contribuiçóes das perspectivas de Paul Ricoeur, Walter Benjamim e da antropologia médica. Ciência e Saúde Coletiva. Rio de Janeiro, v. 18, n. 10, p. 2.847-2.857, 2013.

PALOMBINI, A. L. et al. Relação entre pesquisa e clínica com estudos de cogestão com usuários de saúde mental. Ciência e Saúde Coletiva. Rio de Janeiro, v. 18, n. 10, p. 2.899-2.908, 2013.

RABELO, M. C.; ALVES, P. C.; SOUSA, I. M. Introdução. In: Experiência de doença e narrativa. Rio de Janeiro: Fiocruz, 1999.

SERPA JR., O. et al. Experiência, narrativa e conhecimento: a perspectiva do psiquiatra e do usuário. Physis, Rio de Janeiro, v. 24, n. 4, p. 1.053-1.077, 2014.

\section{Notas}

${ }^{1}$ R. A. Pacheco participou da idealização, pesquisa e primeira redação do artigo. R. O. Campos, da revisão, pesquisa e segunda redação do artigo. 


\section{Abstract}

\section{"Narrative-experience" as a syntagma of empty nucleus: contributions to the methodological debate in the field of Collective Health}

The production and analysis of narratives is a methodological instrumental used in qualitative studies in the field of Collective Health. The article locates some grounds for the use of the concept of narrativeexperience as a methodological-conceptual strategy for this research field. The paradoxical articulation always present between the terms experience and narrative is investigated and situated theoretically from the concept framework in Walter Benjamin. For this author, there is no experience except in language. This is the crucial point from which narrative experience is situated in this text as an empty nucleus syntagm, a way of surrounding the central paradox of the transmission of spirit in language qualifying the bases for the concept use as mediation between experience and culture and contributing to the methodological debate in the field of Collective Health.

> Keywords: experience; narrative; methodology; fundamentals; planning. 